\title{
Distribution of Eye Diseases in Kasungu District, Malawi, Central Africa-A Retrospective Cross-Sectional Study
}

\author{
Richard Kang1, Jae Jun Kim², Paul Chung'3 , Gyuri Hwang4, Jung Sung Kim5, \\ Seunghan Baek ${ }^{6}$, Eun Jung Im $^{7}$, George Talama ${ }^{8 *}$ \\ ${ }^{1}$ The School of Public Health, UC Berkeley, Berkeley, CA, USA \\ ${ }^{2}$ College of Agriculture and Life Sciences, Cornell University, Ithaca, NY, USA \\ ${ }^{3}$ The Biology Department, Allegheny College, Meadville, PA, USA \\ ${ }^{4}$ Korea International School, Gyeonggi-do, South Korea \\ ${ }^{5}$ Henry M. Gunn High School, Palo Alto, California, USA \\ ${ }^{6}$ Department of Computer Science, Johns Hopkins University, Baltimore, MD, USA \\ ${ }^{7}$ Classics, College of Letters, Arts and Sciences, USC, LA, USA \\ ${ }^{8}$ Kasungu District Hospital, Kasungu, Malawi \\ Email: ^gctalama@gmail.com
}

How to cite this paper: Kang, R., Kim, J.J., Chung, P., Hwang, G., Kim, J.S., Baek, S., Im, E.J. and Talama, G. (2018) Distribution of Eye Diseases in Kasungu District, Malawi, Central Africa-A Retrospective Cross-Sectional Study. Advances in Infectious Diseases, 8, 64-69.

https://doi.org/10.4236/aid.2018.82008

Received: February 27, 2018

Accepted: June 9, 2018

Published: June 12, 2018

Copyright (ㅇ 2018 by authors and Scientific Research Publishing Inc. This work is licensed under the Creative Commons Attribution International License (CC BY 4.0).

http://creativecommons.org/licenses/by/4.0/

\section{(c) (i) Open Access}

\begin{abstract}
Analysis of eye diseases of patients at Kasungu District Hospital in Malawi was made. Malawi is one of the poorest countries in the world and the health system faces a lot challenges in terms of resources. The study was, therefore, done to understand the burden and distribution of eye diseases in this resource-limited setting. A retrospective study was conducted by extracting data from data registers in the outpatient eye department for the period of May 2015 to June 2016. The data of the reported eye diseases analyzed with variables such as patient gender, eye disease type, patient age and times of the year. There was no association between eye diseases and gender nor with times of the year. However, it was noted that the commonest type of eye disease was conjunctivitis. And, there was strong association of some disease type with age, for example, conjunctivitis was common in young age group while cataract was common in the elderly. It was shown in this study that many of the eye diseases endemic in Africa do generally occur in this selected district as well. However, the analysis presents the possibility of reducing the incidences of many diseases by preventive measures and access to health facilities on time.
\end{abstract}

\section{Keywords}

Eye Diseases, Kasungu District, Malawi 


\section{Introduction}

Eye diseases affect everyone in the world, what usually differs is disease pattern depending on age, gender, religion and climatic conditions. The distribution of eye diseases and causes of blindness in developing and developed nations often differ [1]. Many of the eye diseases that cause blindness are potentially preventable and curable. Many studies have been conducted on pattern of eye diseases in developed countries. However, scanty data exists on the extent or burden of eye diseases in developing countries, especially on non-vision impairing diseases, despite contributing majority of the consultations in eye clinics [2] [3].

The common ocular diseases worldwide are cataract, glaucoma, conjunctivitis, corneal ulcers, uveitis, refractive errors, and pterygium. Some studies done in Nigeria and Sudan hospitals showed that cataract was the most common eye disease seconded by conjunctivitis [4] [5] while conjunctivitis was the most common eye disease seconded by cataract at one of the hospitals in Ghana [6]. In a study conducted in Palestine, refractive errors were the commonest eye disease seconded by conjunctivitis [7].

The study was conducted at Kasungu District Hospital, in Malawi. Kasungu District Hospital is a Ministry of Health hospital and all the services including eye services are free of charge. The hospital serves a population of about 800,000 people and serves both as a primary and secondary care health facility. The pattern of eye diseases at the hospital is not known neither is there any of such data in Malawi.

The aim of this study was to determine the distribution of eye diseases at $\mathrm{Ka}$ sungu District Hospital and to compare the findings with previous studies done in other African countries. This information would help policy makers in the district in coming up with better intervention programmes for eye diseases.

\section{Methodology}

This was a retrospective study and involved retrieving data from outpatient eye department registers between $1^{\text {st }}$ May 2015 and $30^{\text {th }}$ June 2016. All clients, regardless of age, who came to the eye department to sick medical attention, were included in the study. The eye department had one optometrist and two ophthalmic clinical technicians (who work like ophthalmologists) during the time the study was conducted. Patients were seen first by ophthalmic clinical technicians then to optometrist if they had any refractive errors or any condition requiring his attention. Assessment of visual acuity and other anterior eye segment was done by Snellen's chart, slit lamp and torch. Posterior eye segment examination was performed using ophthalmoscope and fundoscopy. After assessment, the clinicians made prescription and dispersed drugs within the department. Documentation of the patient details was done in a hard copy register within the eye department.

The following data elements were extracted from the hard copy register: patient identification, age, gender, diagnosis and date when the patient came to 
hospital. The data entry and analysis was done using Microsoft excel. Analysis included frequency distribution by age groups, gender and diagnosis.

\section{Results}

A total number of 7265 patients were included in the study, out of which 3197 (44\%) were males and 4068 (56\%) were females (Figure 1). Forty one per cent (40\%) of the patients were 20 years and below, $34 \%$ were aged from 21 to 40 years and $26 \%$ were above 40 years (Figure 2).

The most common eye disease was conjunctivitis (51\%). This was followed by refractive errors $(30 \%)$, vernalis $(7 \%)$ then cataract $(3 \%)$, the rest contributed by other conditions (Figure 3). It was noted that no particular eye disease was associated with gender (Figure 4). And, all eye diseases were not associated with any particular time of the year (Figure 5).

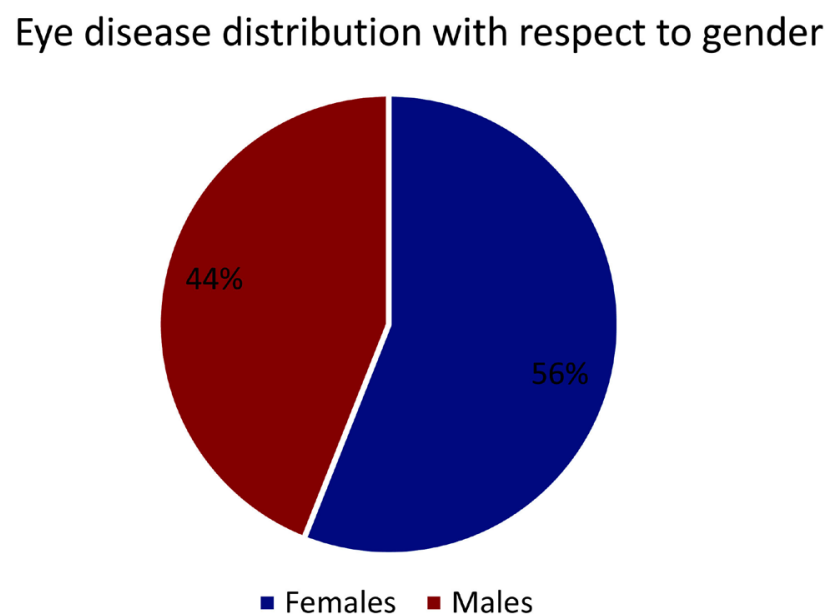

Figure 1. Eye disease distribution between males and females.

\begin{tabular}{ccc}
\hline Age group (Years) & Number of patients & Percentage of patients \\
\hline 0 to 5 & 1362 & $19 \%$ \\
6 to 10 & 479 & $7 \%$ \\
11 to 20 & 1123 & $15 \%$ \\
21 to 30 & 1283 & $18 \%$ \\
31 to 40 & 1149 & $16 \%$ \\
41 to 50 & 730 & $10 \%$ \\
51 to 60 & 540 & $7 \%$ \\
61 to 70 & 336 & $5 \%$ \\
71 to 80 & 217 & $3 \%$ \\
81 to 90 & 37 & $1 \%$ \\
91 to 100 & 9 & $0 \%$ \\
Total & 7265 & $100 \%$ \\
\hline
\end{tabular}

Figure 2. Eye disease distribution by age. 


\section{Frequency of eye diseases}

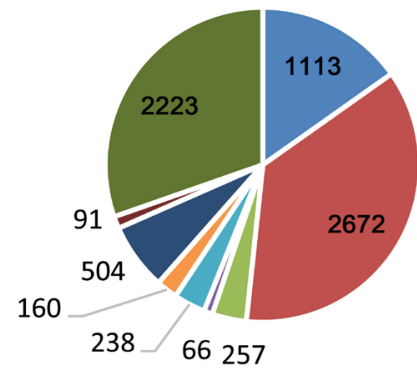

$$
\begin{array}{lll}
\text { - A. Conj. } & \text { - B. Conj. } & \text { - Cataract } \\
\text { - Blephalitis } & \text { - Foreign Body } & \text { - Pinguicula } \\
\text { - Vernalis } & \text { - Pterygium } & \text { - Refractive errors }
\end{array}
$$

Figure 3. Frequency of eye diseases.

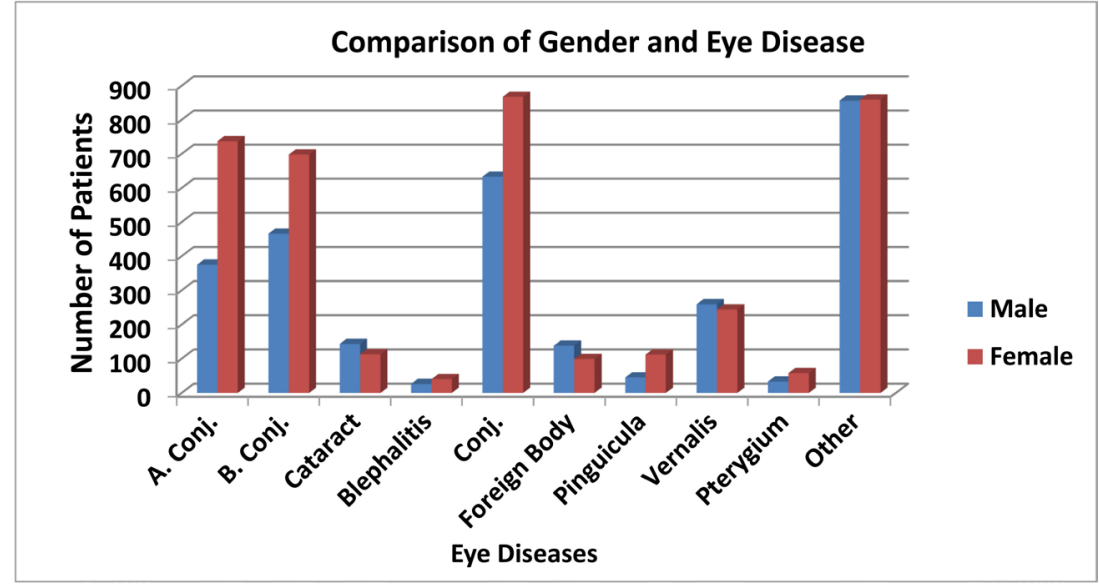

Figure 4. Comparison of gender and eye disease.

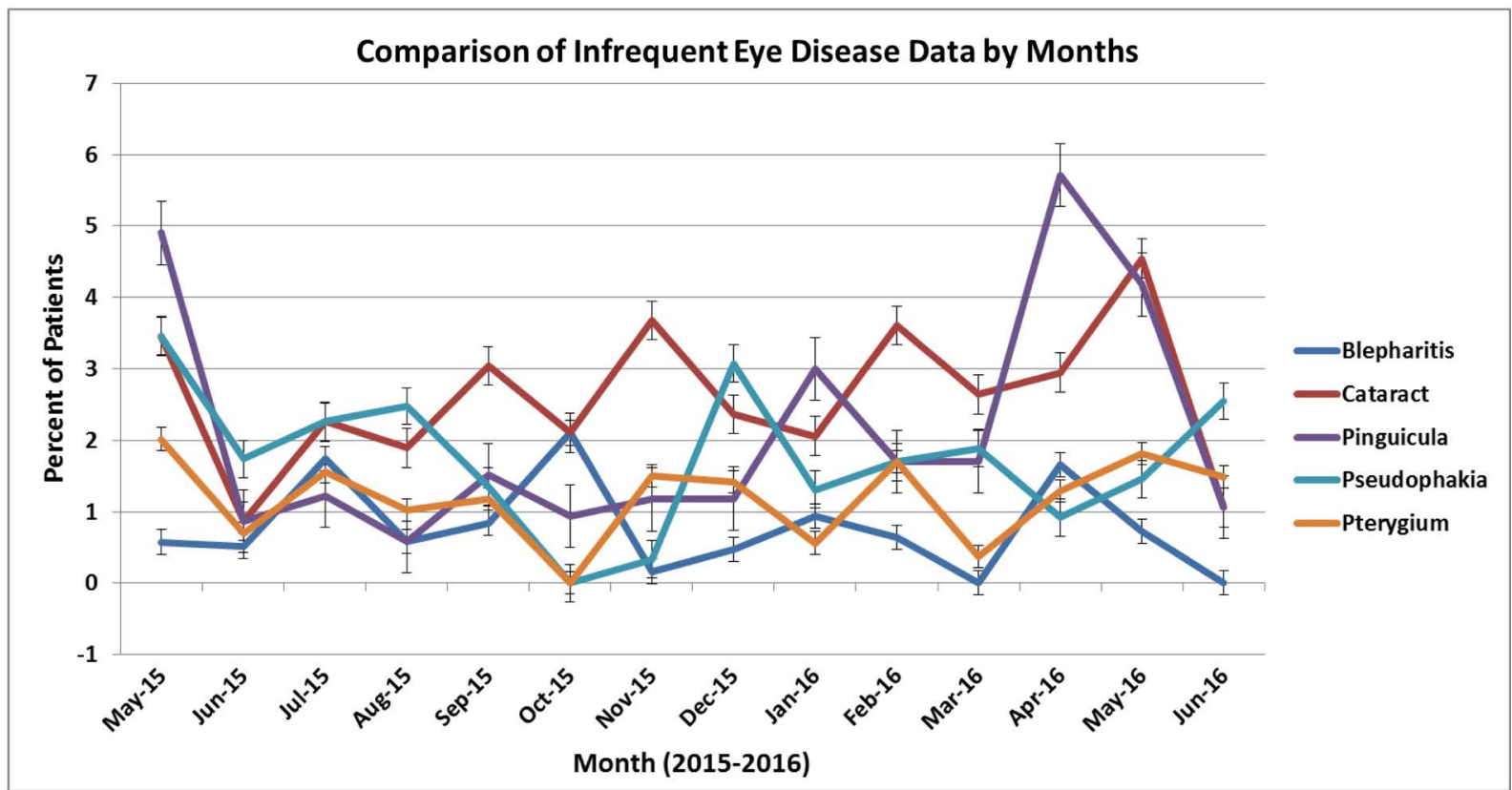

Figure 5. Linear graph shows distribution of eye diseases in different times of the year. 


\section{Discussion}

The study showed that females (56\%) were more in attendance than males (44\%) at the hospital. This was also observed in studies done in Malawi [8], Sudan [4] and Ghana [6]. This is usually because females have a better health seeking behavior than males.

More adults ( $>20$ years old) had eye diseases in this study than children. Studies done in Sudan [4] and South-Western Nigeria [9] reported a similar trend though the difference observed in latter was not statistically significant. A likely explanation for this is that children may not be able to explain their problems properly and hence may not present to the hospital until the features are prominent enough to be noticed by their parents or guardians.

Conjunctivitis was the commonest cause of eye disease in our study, seconded by refractive errors. Vernalis and cataract were third and fourth leading causes of eye disease, respectively. Studies done in Ghana [6] and Pakistan [10] hospitals also reported conjunctivitis as the highest leading cause of ocular morbidity, $39.7 \%$ and $35.6 \%$, respectively. However, studies done in Nigeria [5] and Sudan [4] hospitals reported cataract as the most common eye disease. The study done in Ghana [6] reported cataract as number two (24.4\%), then glaucoma (9.7\%) and the least common was refractive errors. While, the Sudan study reviewed conjunctivitis as second most common ocular morbidity and the least was refractive errors.

There was no specific time of the year that a particular eye disease was associated with. And, we did not find any study that had reported on this. In addition, no particular eye disease was more common in a particular gender, This is unlike the study done by Ajaiyeoba [9] which reported ocular disorders being higher in females than males.

\section{Conclusion}

In conclusion, many of the eye diseases endemic to Africa do generally occur in this selected district as well. It is essential that the district health leadership organizes community education and early treatment to reduce prevalence of these diseases in the community. A more extensive survey would help in coming up with even better information regarding the status of eye disease distribution in the district.

\section{Acknowledgements}

The authors acknowledge the STEM Research Institute and Youth with Talents for sponsoring this medical project. The cooperation of the authorities of Kasungu District Hospital is gratefully acknowledged.

\section{Conflict of Interests}

The authors have not declared any conflict of interests. 


\section{References}

[1] Kawuma, M. (2000) Eye Diseases and Blindness in Adjumani refugee Settlement Camps, Uganda. East African Medical Journal, 77, 580-582.

[2] Adeoye, A.O. and Omotoye, O.J. (2007) Eye Disease in Wesley Guild Hospital, Ilesa, Nigeria. African Journal of Medicine and Medical Sciences, 36, 377-380.

[3] Brilliant, L.B., Pokhrel, R.P., Grasset, N.C., Lepkowski, J.M., Kolstad, A., et al. (1985) Epidemiology of Blindness in Nepal. Bull World Health Organ, 63, 375-386.

[4] Lakho, K.A. and Mohamed Ali, A.B. (2015) Pattern of Eye Diseases at Tertiary Eye Hospital in Sudan (Makah Eye Hospital, Khartoum). Albasar International Journal of Ophthalmology, 3, 15-18. https://doi.org/10.4103/1858-6538.169304

[5] Ogwurike, S. (2004) Pattern of Eye Diseases in Kaduna State-A Rural Community Outreach Experience. Nigerian Journal of Ophthalmology, 12, 1-5.

[6] Agyemang-Mireku, F. (2017) Pattern of Ocular Conditions among Patients Attending an Eye Clinic in Ghana. Optometry: Open Access, 2, 122.

[7] Droos, M. (2013) Pattern of Eye Disease in Patients Attending the Jordanian Field Hospital in Gaza Strip. JRMS March, 20, 33-36. https://doi.org/10.12816/0000051

[8] Kalua, K., Lindfield, R., Mtupanyama, M., Mtumodzi, D. and Msiska, V. (2011) Findings from a Rapid Assessment of Avoidable Blindness (RAAB) in Southern Malawi. PLoS ONE, 6, e19226. https://doi.org/10.1371/journal.pone.0019226

[9] Ajaiyeoba, A.I., et al. (2006) Prevalence and Causes of Eye Diseases amongst Students in South-Western Nigeria. Annals of African Medicine, 5, 197-203.

[10] Saeed, N., et al. (2008) Pattern of Common Eye Diseases in Children Attending Outpatient Eye Department Khyber Teaching Hospital. PakJ Opthalmol, 24, 166-170. 